\title{
Em memória de Florestan Fernandes
}

\section{MIRIAM LIMOEIRO CARDOSO}

$\mathrm{F}$ LORESTAN FERNANDES morreu às $2 \mathrm{~h} 30$ do dia 10 de agosto passado, aos 75 anos de idade. O Brasil perdia um de seus grandes intelectuais, a Sociologia científica no Brasil o seu fundador e expoente maior, a Ciência Social mundial um de seus formuladores de primeira grandeza, os oprimidos e excluídos um de seus representantes mais fiéis e corajosos, o socialismo um de seus defensores mais ardorosos e combativos. A humanidade perdia um homem raro, porque plenamente íntegro.

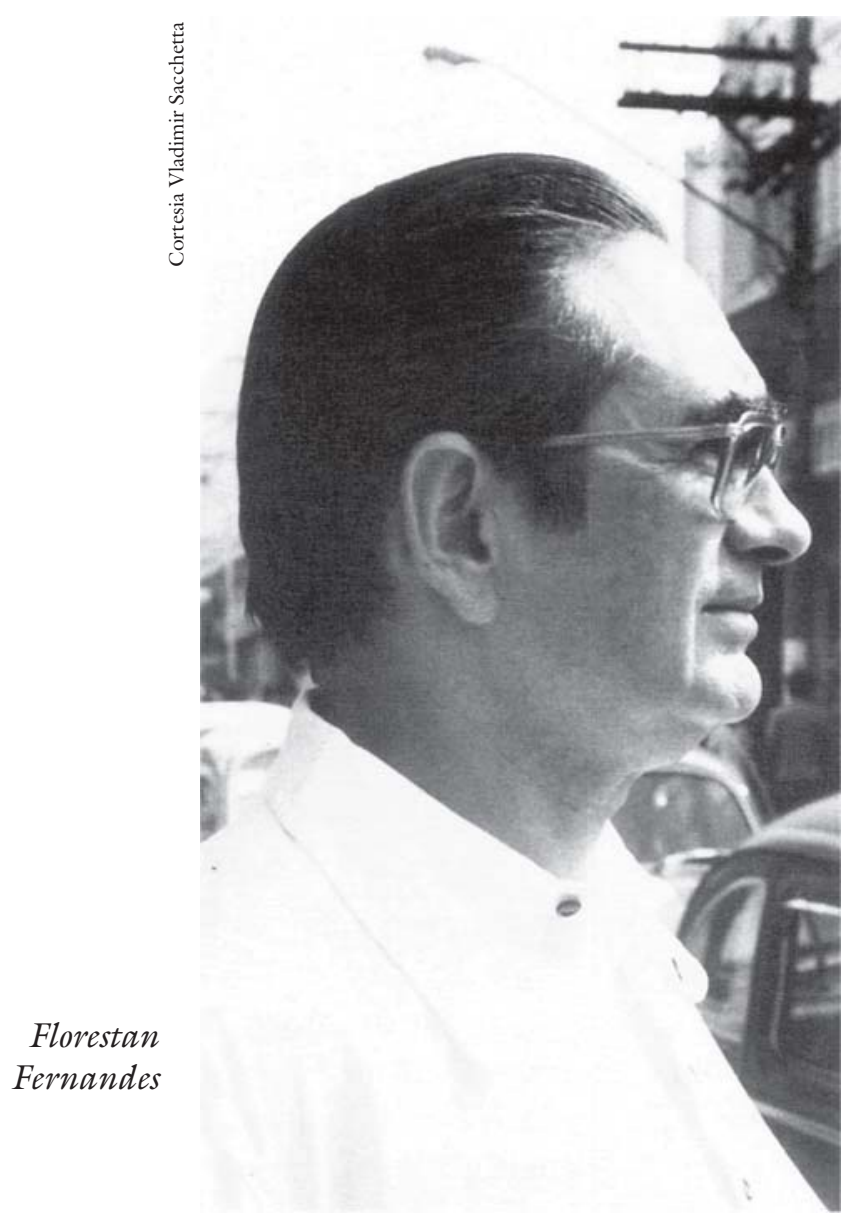

Florestan Fernandes nasceu e viveu sob condições muito adversas. Filho de imigrante portuguesa, empregada em serviços domésticos, habitou moradias muito pobres, deslocando-se de uma a outra com freqüência. Enquanto criança e adolescente, não teve acesso regular à escola. Começou a trabalhar aos sete anos para ajudar seu próprio sustento e o de sua mãe. Foi entregador de compras, engraxate, ajudante de alfaiate, garçom. Desde pequeno, porém, lia sempre, muito, tudo que podia. Estudando nas bibliotecas públicas, fez curso de madureza e ingressou na Universidade de São Paulo, onde se tornaria Professor Doutor, LivreDocente, Professor Titular, Professor Catedrático, Professor Emérito. Na Universidade, alcançou as posições mais altas e destacadas, como responsável pela cadeira de Sociologia I, como formador de toda uma geração de importantes cientistas sociais, 
como um dos principais construtores do Departamento de Ciências Sociais da USP, voltado para a pesquisa científica sistemática e rigorosa e para a formação teórica e técnica de alto nível. Da USP só viria a afastar-se em decorrência de ato arbitrário da ditadura militar que o aposentou compulsoriamente em abril de 1969, quando se tornou professor de Sociologia, como Latin American in Residence, na Universidade de Toronto, no Canadá (1969/1970). De 1970 a 1972 foi professor titular da mesma Universidade. Em fins de 1972 decidiu se afastar da vida universitária acadêmica institucional, por entendê-la limitada e isolada culturalmente.

A ciência que Florestan Fernandes praticava, na pesquisa e no ensino, era assumida como éticamente responsável, socialmente comprometida. Entendia como incompatíveis ciência e ordem social iníqua. Nesta perspectiva, ser cientista era para ele uma forma de atividade militante, engajada, voltada para a transformação social, através da ótica dos dominados. Daí decorre a enorme coerência de sua obra tão vasta. Escreveu mais de 50 livros, entre os quais se pode destacar: A revolução burguesa no Brasil (1975), Sociedade de classes e subdesenvolvimento (1968), Capitalismo dependente e classes na América Latina (1973), A organização social dos Tupinambá (1949), A função social da guerra na sociedade Tupinambá (1952), A integração do negro na sociedade de classes (1964), O negro no mundo dos brancos (1972), A Sociologia no Brasil (1977), A condição de sociólogo (1978), Fundamentos empíricos da explicação sociológica (1967), A Sociologia numa era de revolução social (1962), Mudanças sociais no Brasil (1960), Elementos de sociologia teórica (1970), A ditadura em questão (1982), Circuito fechado (1976), Brasil: em compasso de espera (1980), A universidade brasileira: reforma ou revolução? (1975) etc.

Ao se afastar da função docente na Universidade, Florestan Fernandes a ampliou, passando a ser mais propriamente publicista e político, enquanto colaborador freqüente de importantes jornais de circulação nacional (Folha de $S$. Paulo, Jornal do Brasil), retomando uma atividade que já desenvolvia desde estudante universitário (especialmente em $O$ Estado de S. Paulo e Folha da Ma$n h \tilde{a})$. Seus artigos conjugam sempre horizonte político transformador e inconformista com reflexão e análise crítica, conseguindo um alcance efetivamente formador e em larga escala.

A partir da Constituinte e por dois mandatos consecutivos, Florestan Fernandes foi Deputado Federal pelo Partido dos Trabalhadores. Nesta condição, retomou as antigas lutas que havia liderado na Campanha de Defesa da Escola Pública, então como uma das mais brilhantes e atuantes expressões do Fórum Nacional em Defesa da Educação Pública e Gratuita no Congresso Nacional. Lá se destacou no encaminhamento e no apoio às lutas populares e democráticas em geral, mas suas contribuições mais significativas se situaram, além da educação pública, nas questões dos negros e dos povos indígenas. 
Com sua morte, da sua militância direta fica o seu exemplo e a sua inspiração. Para aqueles que o amavam e o admiravam - como pessoa, como intelectual e como político - fica a sua lembrança e uma grande saudade. Sua obra, porém, já está inscrita na história das Ciências Sociais e, neste sentido, é perene. Como ela é instauradora de um universo de problemas próprio e original que ainda é fecundo para o entendimento e a explicação da nossa realidade social, nos ensinamentos e nos desdobramentos desta obra, Florestan Fernandes continua vivo entre nós.

Miriam Limoeiro Cardoso, socióloga, é professora do Departamento de Ciências Sociais da Universidade Federal do Rio de Janeiro (UFRJ). Foi colaboradora plena do Instituto de Estudos Avançados da USP de setembro de 1994 a abril de 1995, período em que desenvolveu a fase inicial da primeira etapa do projeto de pesquisa Para uma história da Sociologia no Brasil: a obra de Florestan Fernandes. 


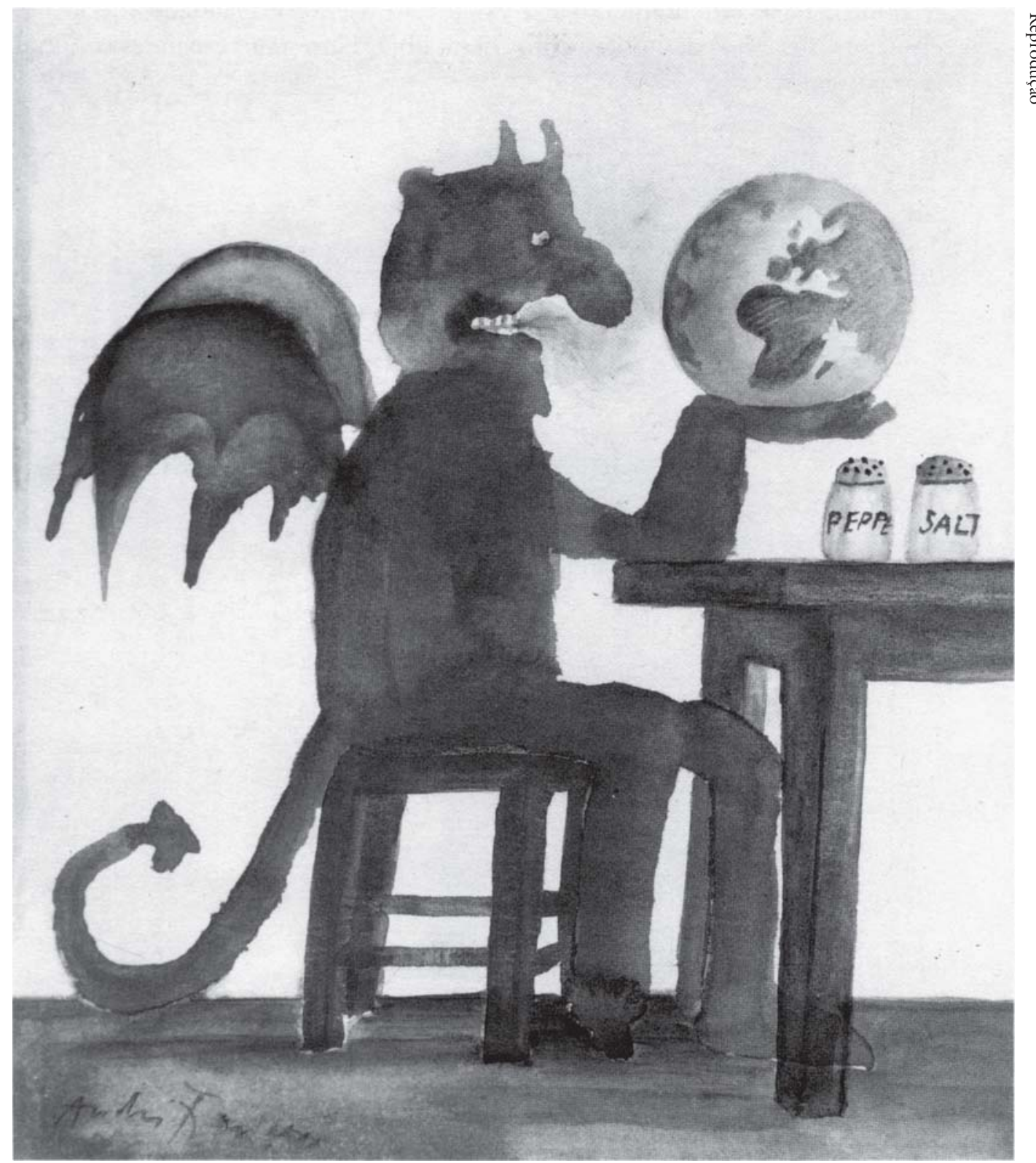

Sal é pimenta, de André François, 1971. Aquarela, Col. Galeria Etcetera, Alemanha 